\title{
Short-Review
}

\section{Insomnia During the COVID-19 Outbreak in Brazil}

Marco Orsini ${ }^{* *}$, Jacqueline Stephanie Fernandes do Nascimento ${ }^{\star}$, Marco Azizi ${ }^{\ddagger}$, Carlos Eduardo Cardoso ${ }^{\dagger}$, Renata Castro $\$$ Nicolle dos Santos Moraes Nunes $\$$ Janie Kelly Fernandes do Nascimento

Como citar esse artigo. Orsini, M.; Do Nascimento, J. S.F.; Azizi, M.; Cardoso, C.E.; Castro, R.; Nunes, N.S.M.; Do Nascimento, J. K. F. Insomnia During the COVID-19 Outbreak in Brazil. Revista de Saúde. 2020 Jan./Jun.; 11 (1): 84-86.

\begin{abstract}
The outbreak of COVID-19 among humans in Brazil and its spread around the world is strongly impacting mental health. Health problems such as anxiety, depression, insomnia and fear were the most related. High levels of stress during the day can impair quality and time of sleep. The purpose of this article was to update, through a bibliographic search, the effects of the pandemic on sleep disorders, with insomnia being the most related. A systematic search had been carried out in the main databases: Lilacs, Bireme and PubMed. The languages used in the search were Portuguese and English, from articles published this year. Using the following keywords: Sleep quality, COVID-19, Insomnia, Cognitive behavioral therapy. The concern about financial and political uncertainties, feelings of impotence and fear of self-contamination and of family members are factors that corroborate with the worsening of the sleep quality of the population and health professionals' working on the front lines of the fight against the pandemic, leading to increased cases of insomnia. Behavioral Cognitive Therapy, hypnotherapy and social interaction mediated by Web conferencing tools are the best ways to treat these symptoms at the moment. Even so, the brazilian literature on the subject is extremely scarce, making it an extremely relevant subject for future research.
\end{abstract}

Keywords: Insomnia, COVID, pandemics.

\section{Introduction}

The outbreak of COVID-19 coronavirus among humans in Brazil and its spreading around the globe is heavily impacting on the health mental ${ }^{1}$. Health problems such as anxiety, depressive, insomnia and fear was the most related. Increased levels of stress during the day, can disrupt sleep quality and time ${ }^{2}$. In addition, sleep disturbances can have direct consequences upon next day emotional functioning ${ }^{3}$.

Insomnia, is the most prevalent sleep disorder worldwide, and confer risks for both physical and mental health. Furthermore, insomnia is associated with considerable direct and indirect healthcare costs ${ }^{3}$. Current treatment approaches are related to cognitive behavioral therapy and hypnosis. Obviously, drug treatment is one of the pillars for resolving insomnia problems, whether or not it is associated with the approaches mentioned above.

Our group suggest some options: cognitive behavioral therapy; exercise programs and social interaction through computer programs and conference calls. In a study conducted by Zhang et $\mathrm{al}^{4}$, composed of a total of 1,563 participants, five hundred and sixty- four $(36.1 \%)$ had insomnia, according to the Insomnia Severity Index (ISI). Such results were related to the level of education, home-office, concerns and fear of infection, feelings of worthlessness, lack of psychological support and drastic information from social media. In conclusion, subsyndromal mental health problems, such as insomnia problems, are a common response to the COVID-19 pandemic.

Roth et $\mathrm{al}^{5,9}$ compared patients with sleep disorders to people with normal sleep patterns and the results suggested a relation between sleep disorders and poor health, less energy and worse cognitive functioning. Decreased quality ${ }^{6}, 9$ and productivity ${ }^{7},{ }^{9}$ are frequent occupational losses in these individuals. Cognitive deficits caused by sleep disorders such as inattention, low concentration and memory failures, can also aggravate difficulties in dealing with stressful situations, making decisions and solving problems ${ }^{8},{ }^{9}$

An online survey of 3,637 participants from 31 provinces in Mainland, China, not infected with SARS$\mathrm{CoV}-2$, pointed to a significant increase in new cases of insomnia $(13.6 \%)$ and worsening of pre-existing conditions $(12.5 \%)$. The study shows that worsening insomnia during the pandemic is more associated with women $(\mathrm{OR}=1.52)$, presence of mental illness $(\mathrm{OR}$

Afiliação dos autores:

† Vassouras University, Vassouras, Rio de Janeiro, Brazil.

\$ Iguaçu University - UNIG - Medicine Department, Nova Iguaçu, Rio de Janeiro, Brazil.

* Email de correspondência: orsinimarco@hotmail.com 
$=1.63)$, stress symptoms $(\mathrm{OR}=1.40)$, and increased anxiety severity $(\mathrm{OR}=1.15)$ and depression $(\mathrm{OR}=$ 1.28). In summary, it concludes that individuals free of infection by COVID-19 have shown a high rate of insomnia that may be related to the worsening of anxiety and depression due to fear of contagion and the increasing number of cases, to economic uncertainties, social distance and change in daily routine. The authors foment the idea that, beyond focusing on fighting and preventing infection, psychological and sleep changes should be addressed in the initial phase of the outbreak. ${ }^{10}$

A study carried out in China with 120 medical teams, 60 from a hospital assigned to the front line to combat COVID-19, and 60 to an unassigned hospital, showed through the Pittsburg Sleep Quality Index (PSQI) an average of $16.97+$ - (poor sleep quality). It was also observed that of the medical team on the front line, $61.67 \%$ had medium insomnia and $26.67 \%$ had severe insomnia. The researchers in this article suggest ways to improve the quality of sleep and mental health of these professionals by strengthening the psychological counseling of frontline teams, intervention with exercises and improving management and emergency measures. ${ }^{11}$

Cognitive Behavioral Therapy (CBT) is a modality of psychotherapy that is based on the interpretation of situations that determine how the individual behaves and feels. ${ }^{12}$ Instructions for stimulus control, sleep restriction, relaxation strategies and cognitive restructuring are components of CBT that can be used to treat insomnia. ${ }^{12}$ Studies show that this therapy is more favorable in sleep efficiency than pharmaceutical intervention, as well as presenting more favorable results than the Waiting List (WL) in terms of sleep quality, daytime performance, concentration, productivity, ability to stay awake and mood ${ }^{12,13}$, reduce subjective symptoms of insomnia ${ }^{12}$, 14,15 and improve quality of life ${ }^{12,15}$. It is important to note that, like other therapies for insomnia, CBT also has a relapse rate. In addition, Cognitive Behavioral Therapy can be done through digital information and communication technologies, being an excellent alternative in the context of social isolation.

A study carried out with university students emphasized that $60 \%$ of all those involved suffered from poor sleep quality and $7.7 \%$ of these met the criteria for insomnia disorders. It was possible to infer that cognitive-behavioral therapy stood out as the treatment with the best results in terms of improving sleep quality with hypnotherapy, exclusive attention and relaxation techniques, favoring mental health in a secondary way. Sessions of self-hypnosis, trance, and imagination strategies set the hypnotherapeutic components. ${ }^{14,15}$

The concern with financial and political uncertainties, the feeling of impotence and fear of self-contamination and of their families are factors that corroborate to the worsening of the quality of sleep of the population and of the health professionals working at the front combating the pandemic, leading to an increase in insomnia cases. CBT, hypnotherapy and social interaction mediated by web conferencing tools are ways to combat these symptoms during the pandemic. Even so, the Brazilian literature on the subject is extremely scarce, making it an extremely relevant subject for future research.

\section{References}

1-Torales J, O'Higgins M, Castaldelli-Maia JM, Ventriglio A. The outbreak of COVID-19 coronavirus and its impact on global mental health [published online ahead of print, 2020 Mar 31]. Int J Soc Psychiatry. 2020;20764020915212. doi:10.1177/0020764020915212

2- Altena E, Baglioni C, Espie CA, et al. Dealing with sleep problems during home confinement due to the COVID-19 outbreak: Practical recommendations from a task force of the European CBT-I Academy [published online ahead of print, 2020 Apr 4]. J Sleep Res. 2020;e13052. doi:10.1111/jsr.13052

3- Mengin A, Allé MC, Rolling J, et al. Conséquences psychopathologiques du confinement [Psychopathological consequences of confinement] [published online ahead of print, 2020 Apr 22]. Encephale. 2020;S00137006(20)30075-0. doi:10.1016/j.encep.2020.04.007

4- Zhang C, Yang L, Liu S, et al. Survey of Insomnia and Related Social Psychological Factors Among Medical Staff Involved in the 2019 Novel Coronavirus Disease Outbreak. Front Psychiatry. 2020;11:306. Published 2020 Apr 14. doi:10.3389/fpsyt.2020.00306

5- Li Y, Qin Q, Sun Q, Sanford LD, Vgontzas AN, Tang X. Insomnia and psychological reactions during the COVID-19 outbreak in China [published online ahead of print, 2020 Apr 30]. J Clin Sleep Med. 2020;10.5664/ jesm.8524. doi: $10.5664 /$ jesm. 8524

6- Lammit GK, Weiner J, Damato N, Sillup GP, Mcmillan CA. Quality of life in people with insomnia. Sleep: Journal of Sleep Research and Sleep Medicine. V. 22, n.2, p.379-385, 1999.

7- Edinger JD, Wohlgemuth WK, Radtke RA, Marsh GR, Quillan RE. Does Cognitive-Behavioral insomnia therapy alter dysfunctional beliefs about sleep? Sleep. V. 24, n. 5, p.591-599, 2001

8- Buysse D, Ganguli M. Can sleep be bad for you? Can insomnia be good? Archives of General Psychiatry. v.59, n. 2, p. 137-138, 2002.

9- Muller MR, Guimaraes SS. Impacto dos transtornos do sono sobre o funcionamento diário e a qualidade de vida. Estud. psicol. (Campinas). v. 24, n 4, p. 519-528, 2007. https://doi.org/10.1590/S0103-166X2007000400011.

10- Li Y, Qin Q, SUN Q, SANFORD LD, VGONTZAS NA, TANG X. Insomnia and psychological reactions during the COVID-19 outbreak in China [published online ahead of print. J Clin Sleep Med. 10.5664/jcsm.8524, 2020. doi:10.5664/jcsm. 8524 .

11- Wu K, Wei X. Analysis of Psychological and Sleep Status and Exercise Rehabilitation of Front-Line Clinical Staff in the Fight Against COVID-19 in China. Med Sci Monit Basic Res. v. 26: n. 924085, 2020. doi:10.12659/ MSMBR.924085.

12- Teixeira CM. Terapia cognitivo-comportamental para insônia: revisão sistemática. Dissertação (Mestrado) - Escola Paulista de Medicina, Universidade Federal de São Paulo (UNIFESP), São Paulo, 2015. Available in: http://www.repositorio.unifesp.br/handle/11600/48958. Accessed on: $21 / 05 / 2020$.

13- Espie CA, Inglis SJ, Tessier S, Harvey L. The clinical effectiveness of cognitive behaviour therapy for chronic insomnia: implementation and evaluation of a sleep clinic in general medical practice. Behav Res Ther. v. 39, p.45-60, 2001. https://doi.org/10.1016/s0005-7967(99)00157-6.

14- Schlarb AA, Friedrich A, claßen M. Sleep problems in university students - an intervention. Neuropsychiatr Dis Treat. v. 13:1989-2001, 2017. https:// doi.org/10.2147/NDT.S142067 
15- Friedrich A, Schlarb AA. Let's talk about sleep: a systematic review of psychological interventions to improve sleep in university students. J Sleep Res. 2017. 